\title{
Avaliação em Química Educativa *
}

É normal recorrer à avaliação de conhecimentos para seleccionar estudantes na passagem à fase educacional seguinte ou na entrada para um emprego. Estes exames são geralmente realizados em grande escala tanto a nível regional como nacional. $\mathrm{O}$ ponto a que estes exames podem envolver ou ser influenciados pelos professores é algo que varia de região para região; contudo, este artigo destina-se a todos os professores de química porque sugere algumas alteraçðes positivas do ensino nas aulas, alteraçð̄es que poderão resultar da avaliação de conhecimentos feita aos estudantes.

As técnicas de planeamento de exames em larga escala são cada vez mais sofisticadas, com reflexos positivos nos métodos de ensino nas escolas, fazendo também com que os próprios professores de Química, usem no seu ensino diário avaliaçðes mais construtivas; além disso têm ajudado ao desenvolvimento curricular.

\section{Desenvolvimento das técnicas de avaliação}

$\mathrm{O}$ aspecto mais evidente do progresso na técnica de avaliação é talvez o actual emprego de uma grande variedade de questðes e de métodos (vd. Tabela 1).

Tabela 1 Técnicas que poderão ser usadas para avaiiar os estudantes de química

\footnotetext{
- Questðes objectivas (resposta fixa)

- Questðes estruturadas

- Questðes experimentais

- Exercícios de compreensão

- Exames com consulta de livro

- Exames práticos

- Avaliação interna de um trabalho prático

- Avaliação interna de um trabalho de projecto
}

Um ponto a favor das questðes-tipo ou de métodos múltiplos é o de isso ser mais justo para os candidatos do que o uso de um único processo.

Por exemplo, num exame de química para alunos de 18 anos do Reino Unido, as correlaçð̌es entre as diferentes partes da avaliação foram as indicadas na Tabela 2 .

Tabela 2 Correlaçðes entre as diferentes partes de um exame de química

\begin{tabular}{cccccc}
\hline & Secção 2 & Secção 3 & Secção 4 & Aplicação \\
\hline Secção 1 & \multirow{2}{*}{0.83} & 0.80 & 0.64 & 0.27 \\
Secção 2 & & 0.87 & 0.72 & 0.32 \\
Secção 3 & & & 0.67 & 0.28 \\
Secção 4 & & & & 0.25 \\
\hline
\end{tabular}

Isto mostra que alguns estudantes responderam de modo diferente às várias secçð̄es do exame. É mais justo um sistema de exames que dê aos candidatos a oportunidade de mostrarem que são capazes de fazer melhor em certos tipos de avaliação do que noutros. Se utilizarmos apenas este argumento e verificarmos que todas as correlaçð̃es são elevadas, poderemos ser levados a concluir serem desnecessários diferentes tipos de avaliação pois os estudantes obterão a mesma classificação independentemente do método usado para os avaliar. Mas esta conclusão não tem em conta um aspecto fundamental: um leque de métodos de avaliação é imprescindivel porque, tanto em química aplicada como em química educativa, são usadas várias técnicas e capacidades. Assim, e de forma simplificada, podemos considerar que a química envolve tanto técnicas intelectuais como práticas e por isso ambas devem ser avaliadas, mesmo que depois se chegue à mesma classificação.

Este argumento pode vir a ser aprofundadu mais tarde ao discutirmos que capacidades, técnicas ou finalidades estão associadas a cada uma destas áreas, por exemplo o trabalho prático, e depois tentarmos avaliar cada uma dessas capacidades, etc. Daqui que no Reino Unido, quando os professores são solicitados a avaliar os estudantes em trabalhos práticos, pede-se-lhes para classificarem as capacidades listadas na Tabela 3.

Tabela 3 Capacidades avaliadas durante a avaliação interna de trabalhos práticos

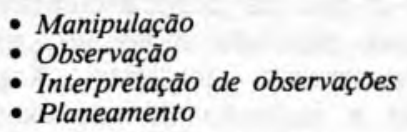

Podia obter-se o seu desenvolvimento como resultado da prática destes trabalhos, porém, pode considerar-se que o sucesso nos trabalhos práticos depende de muito mais do que só destas quatro capacidades. É provável que dependa de qualidades tais como entusiasmo, persistência e respeito pelas consideraçð̄es de segurança que são necessárias quando os estudantes fazem trabalhos práticos. Por isso é normal juntar-se à lista das quatro capacidades que vão ser avaliadas pelos professores, a avaliação das atitudes dos estudantes durante a execução.

Se a finalidade é levar a avaliação destes trabalhos até à reflexão do que é fazer investigação em química, então devemos tentar encorajar os estudantes a fazerem

\footnotetext{
a Departamento de Educação, Universidade de Vork Heslington, York Y01 5DD

* Lição proferida no 6..$^{\circ}$ Encontro Nacional de Quimica. Tradução de Maria Manuela M. da Costa Rosa, Esc. Sec. Sebastião e Silva, Oeiras.
} 
trabalhos de projecto e devemos avaliá-los através de um leque ainda mais pormenorizado de aspectos, tal como indicado na Tabela 4.

Tabela 4 Aspectos do trabalho de projecto que poderão ser avaliados

1. Formulação do problema

2. Investigaçāo de conhecimentos básicos

3. Planeamento da actividade

4. Técnicas laboratoriais

5. Inferências a partir dos trabalhos práticos

6. Inferências relativas aos conhecimentos básicos

7. Apresentação de um relatório

As estatísticas mostram (') que os professores têm dificuldade em identificar os diferentes niveis atingidos pelos estudantes considerados individualmente, em aspectos semelhantes aos acima listados. Isso é, parece que os professores chegam facilmente a uma impressão geral do valor de um candidato e as classificaçōes que dão aos aspectos separados tendem a reflectir esta avaliação geral. Isto pode não ter interesse em si mesmo mas a consideração em separado destes vários aspectos encorajará tanto os professores como as estudantes a dar-lhes a devida atenção. Portanto, o uso de um método de avaliação pormenorizada dos trabalhos práticos poderá ter uma óptima influência no ensino e na aprendizagem nas escolas.

De modo semelhante, a maneira mais justa de avaliar os estudantes nas provas escrita deverá ser através de diferentes tipos de questoes porque alguns estudantes poderão ser melhores em determinados tipos do que noutros, mas também porque essas provas poderão reflectir mais profundamente os aspectos práticos da química educativa ou da química. Por exemplo, Matthews $\left({ }^{2}\right)$ sugere que as questðes estruturadas, nas quais se pð̃e aos estudantes uma sequência de questðes sobre o mesmo tópico, reflectem um bom ensino por conduzirem os estudantes à compreensão através de um questionário cuidadosamente sequenciado. Mihkelson $\left({ }^{3}\right)$ sugere também que as questőes que forem adequadamente sequenciadas podem desenvolver nos estudantes técnicas de resolução do problemas $(4,5)$.

Poderia argumentar-se que na prática cientifica é importante que qualquer cientista saiba ler, analisar e compreender um documento científico. Argumentos como este apoiariam a inclusão de um exercício de compreensão no leque dos métodos de avaliação. Nele, os estudantes leriam um texto científico desconhecido sendo-lhes depois pedido para responderem a questðes sobre o documento. A um nível mais elevado, é importante desenvolver as técnicas associadas à escrita de uma sintese de uma determinada área da química recorrendo a um certo número de fontes. Isto não requer apenas que o estudante compreenda e analise os vários documentos, mas também que escreva uma sintese crítica destes vários documentos. Se acreditamos que estas técnicas são importantes, um exame de consulta (de livro) deveria ser parte integrante do método global de avaliação.

No Reino Unido tentou-se recentemente desenvolver o planeamento dos métodos de avaliação que reflectem a natureza da ciência escolar; para isso, o governo fundou a Assessment of Performance Unit (6) cuja finalidade é: "promover o desenvolvimento de métodos de avaliação e de orientação do sucesso escolar das crianças e procurar identificar 'a incidência do insucesso." Desenvolveram-se, então, métodos para avaliar o su- cesso escolar em seis categorias de actividades científicas (ver Tabela 5).

Tabela 5 Categorias de actividades científicas
1. Usar representação simbólica
2. Usar aparelhos e instrumentos de medida
3. Tarefas de observação
4. Interpretação e aplicação
5. Planeamento de investigaçōes
6. Execução de investigaçðes

Ao redigir-se esta lista, formularam-se critérios que definem a ciência escolar em termos de áreas de resultados. Uma outra iniciativa governamental recente é a redacção dos Critérios Nacionais em termos de conteúdo para cada assunto e, associados a este, critérios relativos ao grau atingido que indiquem o nivel de resultados em termos de compreensão e conhecimentos dos estudantes e que será esperado se eles pretenderem conseguir um certo grau no exame. Isto é mais do que dizer que se alguém consegue uma classificação de $65 \%$ ser-lhe-á conferido o grau 3 num sistema graduado de 1-7; é dizer que alguém a quem foi conferido o grau 3 deverá ser capaz de fazer determinadas coisas - da mesma maneira que ao esperar-se que alguém a quem se deu uma carta de condução seja capaz de fazer certas coisas. Isto pode dar-nos a oportunidade de sairmos do extremo de um sistema de exames de química baseado em normas (que é comum no ensino secundário do Reino Unido) para outro mais baseado em critérios. Contudo, fazê-lo pode exigir-nos o planeamento de exames mais fáceis ou mais informativos. Neste momento a maior parte dos nossos exames é planeada de modo que a classificação média seja $50 \%$, o que tem como consequência, para aqueles que têm menos do que $50 \%$, que o exame nos diga mais acerca do que eles não sabem do que sobre o que sabem.

Este facto foi recentemente realçado numa análise conduzida por Massey $\left({ }^{7}\right)$ que examinou os níveis de mestria conseguidos por estudantes num exame de Quimica. Foi um exame em que se atribui aos candidatos o grau de 1-7. Ele verificou o domínio que os alunos, a quem foram atribuídos determinados graus, tinham sobre o assunto tratado em 59 questðes. Definiu a mestria quando $75 \%$ ou mais do grupo responde correctamente à questão (ver Tabela 6).

Tabela 6 Número de questðes dominadas pelos estudantes que conseguiram determinados graus no exame

Grau atribuido

$\mathrm{N} .^{\circ}$ de questðes, das 59 , dominadas por cada grupo de cada grau

\begin{tabular}{lr}
\hline 1 & 37 \\
2 & 22 \\
3 & 8 \\
4 & 4 \\
5 & 2 \\
6 & 1 \\
7 & 0 \\
\hline
\end{tabular}

Isto implica que embora todos os candidatos tenham sido postos, de modo aproximado, perante o mesmo material ao serem preparados para exame, os candidatos mais fracos dominam muito poucas secçðes dele quando classificados pelo sucesso no exame. Qualquer sistema baseado em critérios necessitaria de um elevado nível de sucesso da parte dos candidatos mais fracos. 
A conclusão que eu gostaria de tirar da primeira parte deste artigo é que, embora seja vulgar que os professores lamentem os efeitos restritivos dos exames, é possivel, começando por reflectir cuidadosamente sobre que técnicas e capacidades desejamos desenvolver nos nossos cursos de Química, planear métodos de avaliação adequados à avaliação destas capacidades e por outro lado encorajar as pessoas a darem mais atenção a estes aspectos.

Não é obrigatório que os professores que utilizam avaliaçð̄es no seu ensino normal estabeleçam níveis de discriminação entre os resultados dos estudantes. Estes professores podem estar mais interessados em conhecer as dificuldades que os estudantes sentem para obter uma indicação do sucesso do seu ensino.

Esta tarefa pode ser abordada de duas perspectivas diferentes. $\mathrm{O}$ aproveitamento dos estudantes é avaliado simplesmente com questðes semelhantes às usadas nos exames públicos, pois este é o método pelo qual eles vão ser avaliados no fim do curso; o professor tenta averiguar com maior profundidade os conhecimentos que os estudantes têm, ou a sua falta.

A maneira ideal de o fazer seria conduzir uma discussão ou uma entrevista com cada aluno. Poderia ser útil ter qualquer motivação para a entrevista como aconteceu com Gilbert e Osborne $\left({ }^{8}\right)$ nas amostras das suas entrevistas. A capacidade dos estudantes para compreenderem um conceito de física foi revelada nesta investigação através de discussð̄es sobre se determinados diagramas descreviam ou não exemplos do conceito, Este processo consumiria na prática demasiado tempo a um professor que $o$ introduzisse na rotina diária normal regular e, por isso, um professor que deseje averiguar regularmente os conhecimentos que os seus alunos conseguiram vai recorrer, provavelmente, a testes escritos. Ao fazê-lo, o professor guiar-se-á pelos progressos nas técnicas de avaliação e pela investigação sobre a compreensão da química que os alunos manifestam.

Neste contexto, é útil a aplicação da hierarquia de capacidades de Bloom ( ${ }^{9}$ ) nos métodos de avaliação. É vulgar incluirem-se nos exames algumas questðes que avaliem as capacidades mais elevadas em vez de questões de simples memorização.

Neste caso, uma questão que foi planeada especificamente para testar a compreensão ou a aplicação de um conceito pode fornecer ao estudante a necessária informação factual. Um exemplo disto seria o de um professor que desejasse testar a compreensão dos estudantes sobre o método de construção da formula de um composto a partir de iôes de carga conhecida; nesse caso o teste deveria fornecer aos estudantes as formulas e as cargas dos iðes a que dizem respeito. A utilização de iőes desconhecidos testará mais tarde a compreensão que os estudantes têm do princípio.

As questðes objectivas de escolha múltipla são talvez as mais atraentes para o professor que quer usar um teste diagnóstico que identifique casos de insucesso e de má interpretação. Podem ser usados para abranger amplamente um dado tópico num período de tempo curto. Deste modo o fluxo normal do ensino é apenas levemente interrompido pelo teste e o professor pode classificar rapidamente as respostas. As questð̋es objectivas num exame normalizado deverão ter certas características de modo a criar uma discriminação satisfatória entre os candidatos. Por exemplo, parece plausível que se mais do que $75 \%$ ou menos do que $25 \%$ dos candidatos seleccionarem a resposta correcta, a questão não deverá ser utilizada.
Este argumento não se destina necessariamente ao professor que planeie um teste diagnóstico porque neste caso será mais importante a informação acerca dos erros que os estudantes cometem do que contar as questões a que cada aluno respondeu correctamente. Então, será melhor usar questð̋es de escolha múltipla nas quais as respostas incorrectas (opçð̃es incorrectas) contêm erros previamente identificados. O teste pode então ser classificado não apenas para se saber quantas respostas correctas houve, mas também quantos estudantes cometeram determinados erros.

Garforth $\left({ }^{10}\right)$ utilizou este caminho quando investigava as dificuldades associadas ao uso das questðes iónicas. Dá-se um exemplo na Tabela 7.

Tabela 7 Qual das equaçóes ionicas que se seguem representa a reacçăo entre a solução de nitrato de prata $\mathrm{e}$ a soluçã̃o de cloreto de bário?

\begin{tabular}{ll}
\hline \multicolumn{1}{c}{ Resposta } & \multicolumn{1}{c}{ Erro } \\
\hline $\begin{array}{l}\text { A. } \mathrm{Ag}^{2+}+2 \mathrm{Cl}^{-} \rightarrow \mathrm{AgCl}_{2} \\
\text { B. } \mathrm{Ag}^{+}+\mathrm{Cl}^{-} \rightarrow \mathrm{AgCl}^{-}\end{array}$ & $\begin{array}{l}\text { Valor da carga do ião } \\
\text { Resposta correcta }\end{array}$ \\
C. $\mathrm{Ba}^{2+}+2 \mathrm{NO}_{3}^{-} \rightarrow \mathrm{Ba}\left(\mathrm{NO}_{3}\right)_{2}$ & $\begin{array}{l}\text { Os iðes "espectadores" não tomam } \\
\text { parte na reação }\end{array}$ \\
D. $\mathrm{Ag}^{+}+2 \mathrm{Cl}^{-} \rightarrow \mathrm{AgCl}_{2}$ & $\begin{array}{l}\text { As ionicas devem apresentar equi- } \\
\text { librio de carga }\end{array}$ \\
E. $\mathrm{Ag}^{+}+\mathrm{Cl}^{-} \rightarrow \mathrm{AgCl}_{2}$ & $\begin{array}{l}\text { As equaçó iónicas devem apresen- } \\
\text { tar equilibrio de massa }\end{array}$ \\
\hline
\end{tabular}

Aqui o problema consiste em como planear as questðes que usam opçð̄es incorrectas que contenham erros que os estudantes têm tendência a fazer, em vez dos erros que os professores julgam que os alunos farão. O que seria ideal era que as questðes fossem planeadas depois de uma investigação preliminar sobre os tipos de interpretaçðes erradas feitas pelos alunos. Sutton ( $\left.{ }^{11}\right)$ proporciona-nos uma resenha preciosa dos processos possíveis para investigar os conhecimentos dos estudantes. Contudo, sem nos tornarmos demasiado sofisticados, é possível treinar os professores na identificação sistemática dos erros mais comuns como introdução ao planeamento de um teste diagnóstico bem organizado. Sucintamente, descrevem-se abaixo três caminhos possíveis.

1. Registe discussర̃es com pequenos grupos de estudantes a quem se tenha pedido para explicarem como chegaram às respostas que deram num teste.

2. Faça pequenas experiências com pequenos grupos de estudantes e registe a discussão havia quando se lhes pede para explicarem o que está a acontecer.

3. Num teste que foi planeado para testar a compreensão, peça aos estudantes que expliquem, escrevendo uma ou duas afirmaçōes, as suas razões para darem a resposta à questão.

Johnstone ( $\left.{ }^{12}\right)$ afirmou recentemente que se deve ter cuidado ao usarmos, nos testes referidos a critérios, as questôes de escolha múltipla visto que, por exemplo, se a maior parte dos estudantes seleccionar a resposta correcta isto pode ser devido mais a que as opçð̄es incorrectas sejam muito pouco plausíveis do que devido a que maior parte dos estudantes tenha compreendido o conceito. Sugere uma forma de questão particularmente interessante que implica que se apresente a in- 
formação aos estudantes sob a forma de uma grelha e que se lhes peça depois que seleccionem informação da grelha para responderem a determinadas questðes. Cada quadrado da grelha está numerado e os estudantes respondem às perguntas escrevendo em baixo os números apropriados. Os estudantes não sabem quantas informaçðes têm de usar e os efeitos de adivinhação estão reduzidos ao mínimo.

Em conclusão, e para ser realista, se a nossa finalidade é mesmo assegurar que o maior número possível dos nossos estudantes passe nos exames públicos, devemos decididamente querer que eles consigam um razoável conhecimento dos tópicos que tenham estudado. Só podemos começar a melhorar este conhecimento se dispusermos, antes de tudo, de métodos seguros que permitam estabelecer que conhecimentos têm os nossos alunos. A intenção deste artigo foi a de mostrar que, para o fazer, temos já à nossa disposição algumas técnicas.

1. Fairbrother, R.W. and Swain, J.R.L. 1977, Assessment of Project Work, Educational Research, 19, 93.
2. Mathews, J.C., Assessment of Students, in Waddington, D.J. (Ed.). Teaching School Chemistry, UNESCO (1983-84).

3. Mihkelson, A.E., 1982, A Piagetian approach to problem solving and chemical education. Education in Chemistry, 19, 24.

4. Ashmore, A.D., Frazer, M.J. and Casey; R.J., 1979, Problem Solving and Problem Solving Networks in Chemistry, Journal of Chemical Education, 56, 377.

5. Selvaratnam, M. and Frazer, M.J. Problem Solving in Chemistry, London: Heineman, 1981.

6. Driver, R. and Worsley, C., 1979, The Assessment of Performance in Science Project. European Journal of Science Education, $1,441$.

7. Massey, A.J., 1982, Assessing $16^{+}$Chemistry. The exposure-mastery gap. Education in Chemistry, 19, 143.

8. Osborne, R.J. and Gilbert, J.K., 1980, A method for investigating concept understanding in science. European Journal of Science Education, 2, 311.

9. Bloom, B.S., Taxonomy of Educational Objectives I, London: Longmans, 1986.

10. Garforth, F.M., Johnstone, A.H. and Lazonby, J.N., 1976, Ionic equations-difficulties in understanding and use. Education in Chemistry, 13, 72.

11. Sutton, C.R., 1980, The learner's prior knowledge: a critical review of techniques for probing its organization. European Journal of Science Education, 2, 107.

12. Johnstone, A.H., Macguire, P.R.P. Friel, S. and Morrison, E.W., 1983, Criterion - referend testing in science - thoughts, worries and suggestions. School Science Review, 64, 626.

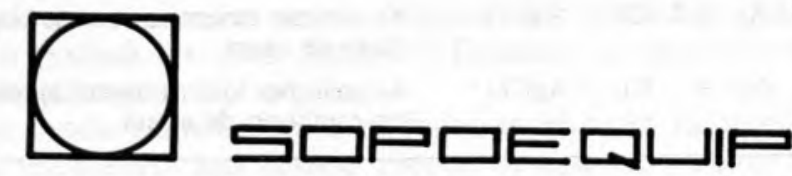

PRODUTOS E EQUIPAMENTOS PARA A INDÚSTRIA E LABORATORIOS LDA

\section{DINAMISMO - QUALIDADE - SERVIÇO}

\section{ESCOLHA - EFICIÊNCIA}

PEÇA-NOS A LISTA DAS NOSSAS REPRESENTADAS

ALGUMA LHE INTERESSARÁ!

Estamos à distância do seu telefone...

QUINTA DA PIEDADE, LOTE $12-1 .^{\circ}$

TEL. 2594462 